\title{
Inhibition of invadopodia formation by diosgenin in tumor cells (Review)
}

\author{
YAXIN LIAN ${ }^{1}$, DEZHONG WEN $^{2}$, XIAOTING MENG ${ }^{1}$, XIAOZHEN WANG ${ }^{3}$, \\ HONGCHENG LI ${ }^{4}$, LIMING HAO ${ }^{1}$, HUI XUE ${ }^{1}$ and JIAZHAO ${ }^{1}$ \\ Departments of ${ }^{1}$ Histology and Embryology, and ${ }^{2}$ Medical Genetics, \\ College of Basic Medical Sciences; ${ }^{3}$ Department of Breast Surgery, The First Hospital, Jilin University; \\ ${ }^{4}$ GeneScience Pharmaceuticals Co., Ltd., Changchun, Jilin 130021, P.R. China
}

Received February 27, 2020; Accepted July 15, 2020

DOI: $10.3892 / \mathrm{ol} .2020 .12148$

\begin{abstract}
Diosgenin is a type of steroid extracted from the rhizome of Dioscorea plants. In traditional Chinese medicine, Dioscorea has the effect of 'eliminating phlegm, promoting digestion, relaxing tendons, promoting blood circulation and inhibiting malaria'. Recent studies have confirmed that diosgenin exhibits a number of pharmacological effects, including antitumor activities. Through its antitumor effect, diosgenin is able to block tumor progression and increase the survival rate of patients with cancer; ultimately improving their quality of life. However, the mechanism underlying its pharmacological action remains unclear. Once tumor cells reach a metastatic phase, it can be fatal. Increased migration and invasiveness are the hallmarks of metastatic tumor cells. Invadopodia formation is key to maintaining the high migration and invasive ability of tumor cells. Invadopodia are a type of membrane structure process rich in filamentous-actin and are common in highly invasive tumor cells. In addition to actin, numerous actin regulators, including cortical actin-binding protein (Cortactin), accumulate in invadopodia. Cortactin is a microfilament actin-binding protein with special repetitive domains that are directly involved in the formation of the cortical microfilament actin cell skeleton. Cortactin is also one of the main substrates of intracellular Src-type tyrosine protein kinases and represents a highly conserved family of intracellular cortical signaling proteins. In recent years, great progress has been made in understanding the role of Cortactin and its molecular mechanism in cell motility. However, the diosgenin-Cortactin-invadopodia mechanism is still under investigation. Therefore, the present review focused on the current research on the regulation of invadopodia by diosgenin via Cortactin.
\end{abstract}

Correspondence to: Ms. Jia Zhao, Department of Histology and Embryology, College of Basic Medical Sciences, Jilin University, 126 Xinmin, Changchun, Jilin 130021, P.R. China

E-mail: zhaojia310@163.com

Key words: diosgenin, invadopodia, Cortactin, tumor metastasis

\section{Contents}

1. Tumor metastasis

2. Formation and function of invadopodia

3. Antitumor effects and mechanisms of diosgenin

4. Structure and regulation of Cortactin

5. Role of Cortactin in invadopodia formation and function

6. Potential diosgenin-Cortactin-invadopodia mechanism

7. Clinical application of diosgenin

8. Conclusions and prospects

\section{Introduction}

Cancer is one of the leading causes of mortality worldwide, it was estimated that 14.1 million new cancer cases and 8.2 million cancer mortalities occurred in 2012, worldwide (1,2). Metastasis is the most dangerous stage in the occurrence and development of cancer (3). Clinically, numerous patients with malignant tumors present with metastases at the time of diagnosis (4). Therefore, the prevention and suppression of tumor metastasis is a critical issue that requires attention.

Tumor metastasis is a complex, multifactorial dynamic process (5). Tumor metastasis involves the activation and interaction of complex signaling pathways in the tumor microenvironment, the invasion and survival of tumor cells in the blood circulatory system or lymphatic circulatory system, and the proliferation of tumor cells at target-shifting sites (6).

Invadopodia is an important structure formed in cancer metastasis, therefore, it is considered promising to investigate the suppression of cancer metastasis from the perspective of inhibiting invadopodia. In addition, the topic concerning traditional Chinese medicine, including diosgenin suppressing cancer metastasis through inhibiting invadopodia has been paid more attention. The present review will discuss and summarize the potential molecular mechanism of diosgenin inhibiting the formation and function of invadopodia.

\section{Formation and function of invadopodia}

Several studies have demonstrated that invadopodia are formed in the early stages of invasion and metastasis of tumor cells $(7,8)$. The invadopodium is an essential structure that is 
involved in the invasion and metastasis of cancer cells (9). The invadopodium is a type of special membrane structure process that is rich in actin and involved in the degradation and remodeling of the extracellular matrix (10). Electron microscopy has revealed that invadopodia are slender, protruding structures (11).

The formation of invadopodia is generally divided into three stages (Fig. 1): i) formation of the core of the invadopodia precursor ii) stabilization of the invadopodia precursor and iii) maturation of the invadopodia (12). The core of the invadopodia precursor is formed by neural Wiskott-Aldrich syndrome protein (N-WASP), the Arp2/3 complex and cofilin recruitment around the actin-Cortactin complex (7). The core can be formed in a few seconds, but it is unstable (13). After the core is formed, tyrosine kinase substrate with $5 \mathrm{SH} 3$ domains (Tks5) rapidly binds the core (within $20 \mathrm{sec}$ ) (14). Tks 5 mediates the binding of the precursor complex to $\mathrm{PI}(3,4) \mathrm{P} 2$ located on the cell membrane to stabilize the precursor structure (14-16). Lamellipodin protein causes the MenaArg-SH2-domain-containing 5 inositol phosphatase (SHIP2) complex (Mena is a well-known cytoskeleton regulator that regulates the assembly of actin filaments and modulates cell adhesion and motility by interacting with Lamellipodin) (17) to be recruited as a precursor $(15,16)$. SHIP2 promotes the production of $\mathrm{PI}(3,4) \mathrm{P} 2$, which is beneficial for fixation of the precursor to the cell membrane and stabilization of precursors. Cofilin and Arp2/3 complexes mediate two different actin aggregation pathways, the cooperation of which greatly enhances further aggregation of actin (18). Actin polymerization then prolongs and forms the invadopodia, resulting in increased matrix metalloproteinase (MMP) content, degraded extracellular matrix and invadopodia maturation $(12,14,19)$.

In other words, to break through the barrier of the extracellular matrix, tumor cells need to extend cellular protrusions, which reconstruct and degrade the extracellular matrix (13). These types of cell protrusions are essential for the ability of tumor cells to break through the basement membrane and vascular wall $(10,13)$. The protruding structures (protrusions) formed by invasive tumor cells on one side of the basement membrane are the invadopodia, which are rich in actin regulatory proteins, adhesion molecules, signaling or receptor proteins, cell membrane recombinant proteins, and matrix proteolytic enzymes (10,13,19-23). Invadopodia are involved in the process of tumor cell invasion through the basement membrane as follows: i) The structure forms first, and then the invadopodia perforate the basement membrane; ii) the invadopodia then elongate and extend through and beyond the basement membrane; and iii) finally, the invadopodia lead to the migration of tumor cells (19).

As invadopodia are so important for cancer metastasis, an improved understanding of the formation of and regulatory mechanism controlling invadopodia is critical. Research results in this field are expected to provide new therapeutic targets and directions for tumor treatment.

\section{Antitumor effects and mechanisms of diosgenin}

Research on the effects of artemisinin against malaria by Youyou Tu (24) won the 2015 Nobel Prize in Physiology or Medicine. Therefore, the discovery of natural products from traditional Chinese medicine may be beneficial for the development of, and investigation into, innovative drugs for other diseases.
Diosgenin (Fig. 2) (25) is a type of steroid extracted from the rhizome of Dioscorea (26-28), it is the hydrolysate of dioscin and is abundant in Dioscorea $(27,28)$. Its multiple pharmacological effects have been confirmed in previous studies; it has been demonstrated to exhibit antitumor $(27,29,30)$ and anti-inflammatory activity $(27,29,30)$, as well as improving cardiovascular function (27), lowering blood lipids $(29,30)$, regulating immunity $(27,29)$, and inhibiting platelet aggregation (31). Diosgenin can also decrease visceral injury and protect visceral organs, including the liver (29,30), kidney (29), brain (29) and gastrointestinal tract $(29,30)$. Diosgenin represents an important raw material for the synthesis of various steroid drugs (27). Research has revealed that the toxicity and side effects of diosgenin are low $(29,32)$.

Diosgenin inhibits the metastasis of various cancers, such as prostate $(28,30,33-36)$, gastric $(30,36-38)$, lung $(39,40)$, breast $(30,41)$, liver $(30)$, renal $(30)$ and colon (41) cancer, and melanoma (29). Diosgenin inhibits metastasis in multiple types of cancer primarily by suppressing constitutively-activated pro-inflammatory and pro-survival signaling pathways and factors (42), such as NF- $\mathrm{BB}$-associated pathways $(28,42,43)$, focal adhesion kinase (FAK)-associated pathways (44), p38/mitogen-activated protein kinase (MAPK) signaling pathways $(42,45)$, and Src (46). Further studies have also found that diosgenin inhibits other functions in tumorigenesis, including tumor cell proliferation, apoptosis, epithelial-to-mesenchymal transition and angiogenesis (33,47-51). Shishodia and Aggarwal (42) revealed that diosgenin inhibits the invasion of human lung cancer $\mathrm{H} 1299$ cells via suppressing TNF-induced NF- $\mathrm{KB}$ activation. Li et al (28) found that diosgenin induces the expression of Src homology 2 phosphatase 2 (SH-PTP2), thus blocking the STAT3-associated signaling pathway, and also that it inhibits the development of human hepatocellular carcinoma. Diosgenin was demonstrated to inhibit tumor growth in both MDA-231 and MCF-7 xenografts in vivo by inhibiting Akt, the Raf/MEK signaling pathway and NF- $\mathrm{B}$ activity to induce apoptosis $(40,52,53)$. Therefore, diosgenin may be a potential option for the treatment of cancer $(27,29,34,35,37,39)$.

\section{Structure and regulation of Cortactin}

Cortical actin-binding protein (Cortactin) has been demonstrated to be associated with cancer. Previous studies have demonstrated that Cortactin is upregulated in a variety of tumors, such as breast cancers and head and neck tumors $(54,55)$. It is involved in a variety of cell activities, including invadopodia formation and cell adhesion, invasion, migration and division $(54,56)$.

Human Cortactin is encoded by the CTTN gene (formerly known as the EMSl gene), which is located on chromosome $11 q 13$ (57). Cortactin protein has three main domains: i) The N-terminal acidic region (NTA); ii) filamentous actin (F-actin) repetitive domain (ABR) and iii) the $\mathrm{SH} 3$ domain in the C-terminal $(54,58)$ (Fig. 3). The NTA binds with Arp in the Arp $2 / 3$ complex and can also regulate the polymerization and shrinkage of F-actin $(54,56,58)$. The ABR is responsible for the binding of Cortactin to F-actin (58). The function of Cortactin is also regulated at the ABR via post-translational modifications $(56,58)$. A study by Uruno et al revealed that 


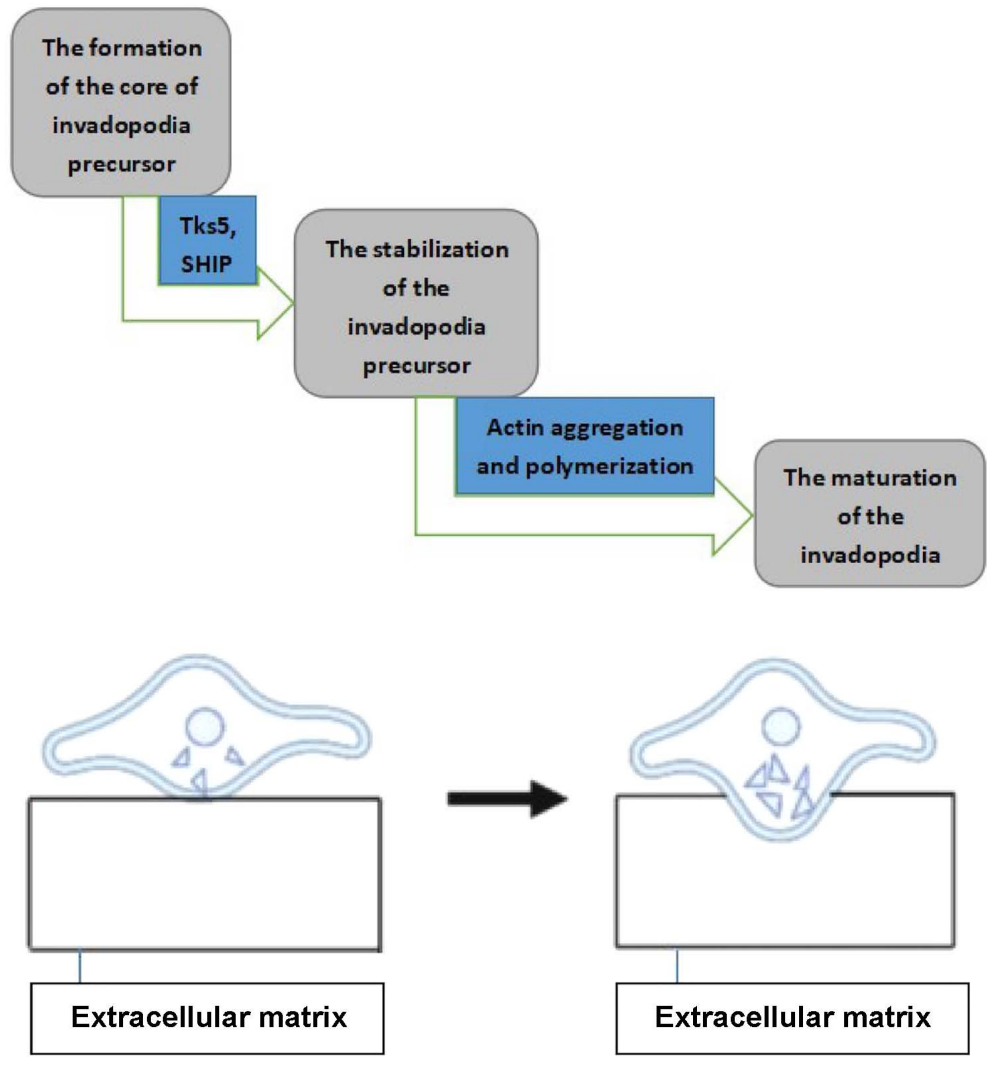

Figure 1. (A) Formation of invadopodia can be divided into three stages. (B) Schematic diagram of the formation and maturation of invadopodia. (created in BioRender.com).

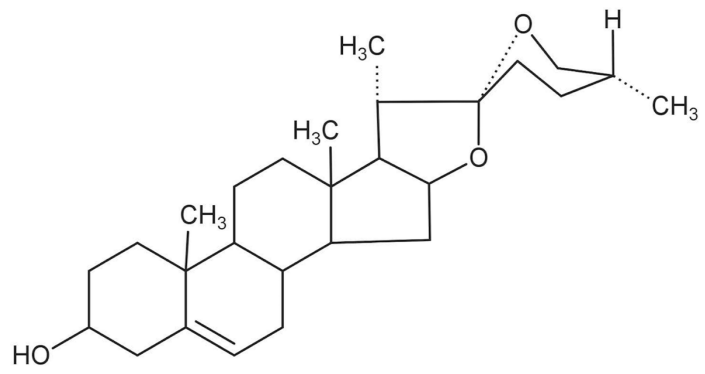

Figure 2. Chemical structure of diosgenin (25). (created with KingDraw).

the number of repeats in the ABRs determines the affinity of Cortactin to F-actin, as well as its ability to regulate cell migration (57). The SH3 domain is a conserved protein module found in various signaling proteins that mediates the interaction with various other proteins, such as neural Wiskott-Aldrich syndrome protein (N-WASP) (59), WASP binding protein (WIP) (60) and missing in metastasis (MIM) (61). The tyrosine phosphorylation of Cortactin is usually associated with the SH3 domain or proline-rich domain-binding proteins (58). The molecular structure of Cortactin changes after phosphorylation, bringing the SH3 domain closer to the $\mathrm{SH} 3$ binding protein, increasing the chances of binding $(54,58)$. Cortactin is the main substrate of the Src family tyrosine kinases, and tyrosine phosphorylation serves an important role in the assembly of cortical microfilament actin (54). Cortactin phosphorylation via $\mathrm{Src}$ kinase is required for invadopodia formation mediated by

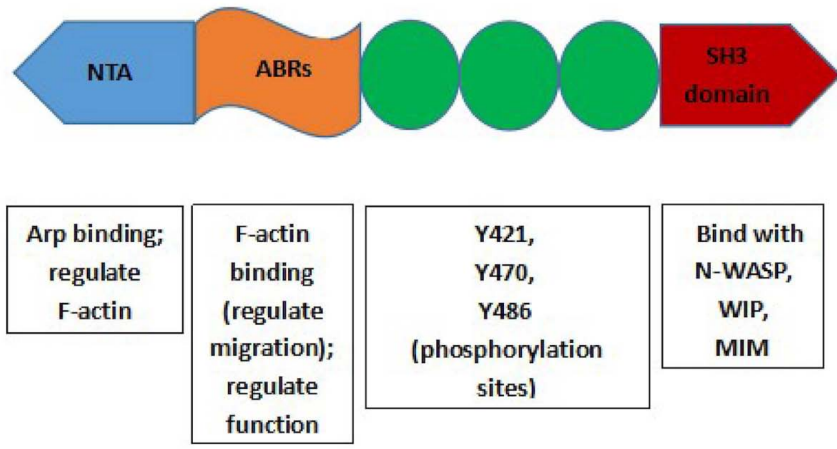

Figure 3. Cortactin consists of parts including NTA, ABRs, phosphorylation sites and SH3 domain (main expression of mentioned parts). NTA, N-terminal acidic region; ABRs filamentous actin repetitive domain; F-actin, filamentous actin; N-WASP, neural Wiskott-Aldrich syndrome protein; WIP, WASP binding protein; MIM, missing in metastasis.

Cortactin $(62,63)$; that is, the Src family tyrosine kinases may promote cell migration via the phosphorylation of Cortactin.

Cortactin and its associated proteins perform functions in the cortical areas associated with cell membrane deformation and the actin cytoskeleton; in pseudopods and cell wrinkles, these proteins enhance the formation and/or stability of dendritic actin networks (64).

\section{Role of Cortactin in invadopodia formation and function}

Invadopodia formation requires numerous proteins $(65,66)$. Cortactin is an actin-binding protein that is closely 


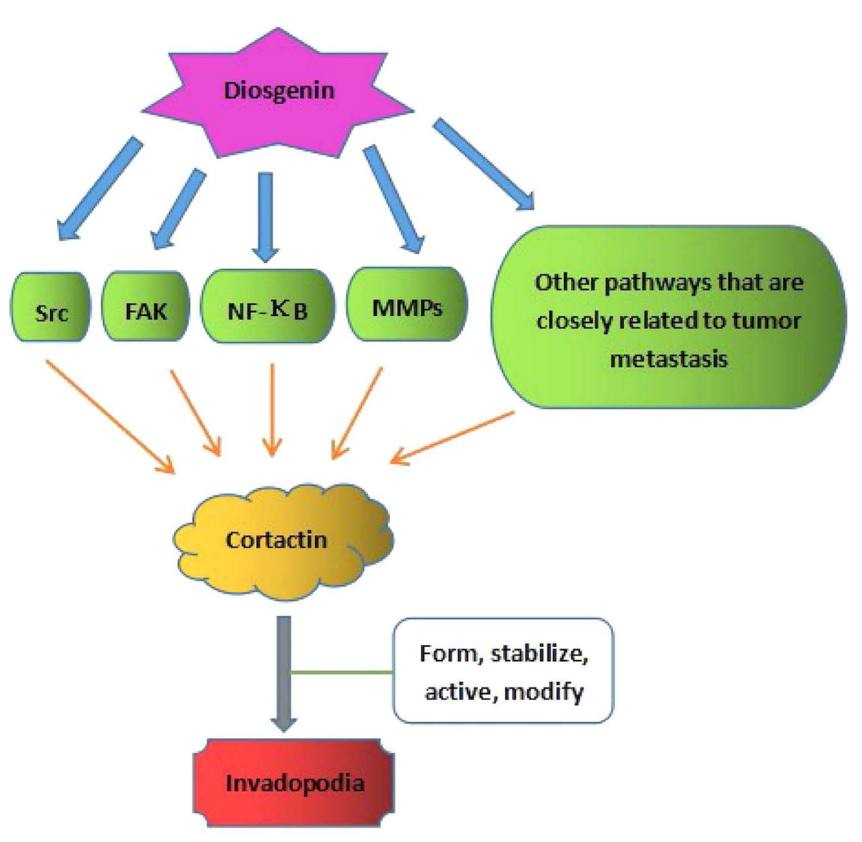

Figure 4. Potential diosgenin-Cortactin-invadopodia mechanism. FAK, focal adhesion kinase; MMPs matrix metalloproteinases; MAPK, mitogenactivated protein kinase.

associated with invadopodia through its interaction with other proteins (67). Cortactin is key for invadopodia formation and interacts with various proteins, such as Arp2/3, N-WASP, and F-actin $(7,65,68)$. Furthermore, Cortactin activates and stabilizes the phases of branched actin assembly via the Arp2/3 complex of invadopodia (69-71). In addition, Cortactin can increase the endurance of invadopodia and promote molecular adhesion and cell movement $(72,73)$.

Previous studies have reported that Cortactin phosphorylation is associated with the rate of cell migration in a number of different types of tumor cell $(54,55,74,75)$. The upregulation of Cortactin promotes the formation of invadopodia, the degradation of the extracellular matrix and the invasiveness of cancer cells $(54,61,76)$. Cortactin is positively correlated with tumor invasiveness and metastasis and is closely associated with the synaptic membrane structure of tumor cells $(54,55,61,76)$.

Other studies have demonstrated that Cortactin binds the Arp2/3 complex and N-WASP and regulates the formation of invadopodia via the Nck1-N-WASP/Arp2/3 signaling pathway $(76,77)$. WASP family proteins can induce the rearrangement of actin molecules in cells by activating Arp $2 / 3$ and thus promote the rapid formation and maturation of invadopodia (78). Genna et al (79) revealed that the tyrosine kinase Pyk2 activates Abl-related gene (Arg) through the EGFR-Pyk2-Src-Arg-cortactin signaling pathway, and directly or indirectly mediates the phosphorylation and polymerization of Cortactin induced by epidermal growth factor (EGF). This results in invadopodia actin polymerization, invadopodia maturation and enhanced invasion of breast cancer cells.

Overall, the aforementioned studies indicate that Cortactin serves a pivotal role in the formation of invadopodia and the degradation of the extracellular matrix to promote cancer cell migration and invasion.

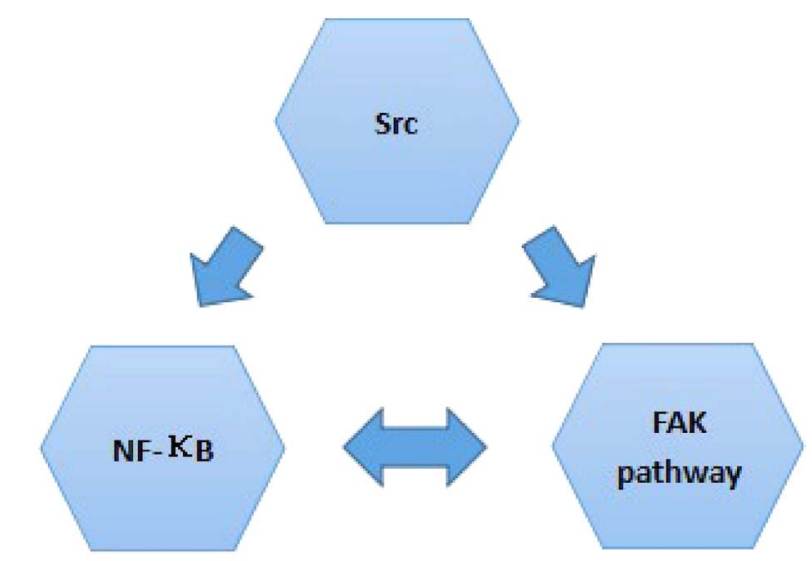

Figure 5. Interactions between $\mathrm{NF}-\kappa \mathrm{B}$, the FAK pathway and Src. FAK, focal adhesion kinase.

\section{Potential diosgenin-Cortactin-invadopodia mechanism}

Invadopodium is a convergence point for a number of signals that regulate tumor cell behaviors, particularly systemic dissemination and metastasis (13). Cortactin is the switch that mediates invadopodia formation $(54,55,67,74,75,80)$. It is regulated by numerous signaling pathways and factors, including the FAK pathway (81), Src (82), NF- $\mathrm{BB}(54,55)$, and other pathways that are closely associated with tumor metastasis $(54,55,74,75,80)$. Several studies have reported that diosgenin is closely associated with the FAK pathway, Src, NF- $\mathrm{B}$ and MMPs $(43,83)$. A potential mechanism of action underlying diosgenin-Cortactin-invadopodia is presented in Fig. 4.

In prostate cancer, diosgenin inhibits MMP expression and, therefore, cancer metastasis (33), while MMP expression promotes cortactin, and both MMPs and cortactin are required for form and function of invadopodia (84). This suggests that the potential mechanism of diosgenin involves the downregulation of MMPs, and inhibition of Cortactin and invadopodia, ultimately inhibiting prostate cancer metastasis. It has also been demonstrated that diosgenin downregulates the $\mathrm{NF}-\kappa \mathrm{B}$ signaling pathway, thus inhibiting the metastasis of prostate cancer, suggesting another mechanism: Downregulation of the NF- $\kappa \mathrm{B}$ signaling pathway results in inhibition of Cortactin, and hence, inhibition of invadopodia (33). In addition, diosgenin can inhibit colon cancer metastasis via regulating the Akt/MAPK signaling pathway (85), while Akt can activate Cortactin $(86,87)$, thus suggesting that diosgenin downregulates the Akt/MAPK signaling pathway, which inhibits Cortactin and hence, inhibits invadopodia, resulting in inhibition of colon cancer metastasis. It was also reported that diosgenin can activate the p38 and JNK pathways and thus inhibit Cortactin in colon cancer (88), suggesting that diosgenin inhibits the formation and function of invadopodia via the downregulation of Cortactin via activating the p38 pathway (89). In breast cancer, it was revealed that diosgenin downregulates Akt, thus inhibiting the metastasis of breast cancer $(40,90)$, similar to the mechanism in colon cancer. Diosgenin can serve as a dual inhibitor of the MEK/ERK and PI3K/Akt signaling pathways to overcome tyrosine kinase inhibitor resistance, resulting in clinical benefits for lung cancer treatment (91). Furthermore, diosgenin downregulates 
the NF-kB-p65/p50 and p38-MAPK pathways and attenuates acute lung injury in mice (92). In human erythroleukemia, diosgenin inhibits the NF- $\mathrm{KB}$ signaling pathway and thus suppresses metastasis (43).

Diosgenin inhibits the activity and amount of transcription factor NF- $\mathrm{KB}(40,93)$, and can also inhibit the function of the FAK pathway (FAK is a regulator of cell migration, proliferation, survival and transcription) (44). In addition, it was found endothelial-cell FAK is required for DNA-damage-induced $\mathrm{NF}-\kappa \mathrm{B}$ activation (94). It was revealed that NF- $\kappa \mathrm{B}$ activation can activate the FAK pathway, which is activated via FAK phosphorylatio $(95,96)$. Tyr397 is the main phosphorylation site of FAK; in addition to its autophosphorylation, Tyr397 can also interact with the SH2 domain of Src family proteins $(97,98)$ to activate other phosphorylation sites, thus promoting the activation of the signaling pathway downstream of the FAK pathway and causing migration and invasion of tumor cells (97,99-101). Furthermore, Src promotes NF- $\mathrm{KB}$ transcriptional activity (102-104), and Src and FAK also serve as a signaling pathway, whereby Src promotes the FAK pathway activity (99-101). The interactions between Src, NF- $\kappa B$ and the FAK pathway are presented in Fig. 5. It was also revealed that diosgenin can decrease the activities of MMP-2 and MMP-9, and the two combined with NF- $\mathrm{kB}$ form an axis (105-108). Inhibiting MMP-2/-9 can suppress the activity of AKT/NF- $\kappa B$ in HeLa cells (107), while suppressing NF- $\kappa B$ can also downregulate MMPs in nude mice which are injected HepG2-HBx cells $(108,109)$. This suggests that the diosgenin mechanism of action may be extensive, involving multiple pathway links that are very complex.

\section{Clinical application of diosgenin}

On the basis of its various functions, diosgenin has been used medicinally to treat a number of diseases and improve several physiological functions. Diosgenin has been applied in many cases, such as treating inflammation $(27,29,30)$, improving cardiovascular function (27), lowering blood lipid levels $(29,30)$ and regulating immunity $(27,29,30)$.

Traditionally, diosgenin was used for the treatment of various symptoms such as cold hands and feet (by its function of activating blood), loss of appetite caused by diseases including cancer, and frequent urination (by its function of protecting kidney) $(27,29,30)$. Currently, diosgenin is widely used for the treatment of cardiovascular diseases $(110,111)$. Several extensive clinical cases (particularly for cardiovascular diseases) have validated diosgenin as a drug for treating diseases (110). In addition, certain studies have demonstrated that psychobehavioral interventions of traditional Chinese medicine can benefit patients with cancer by multiple roles, such as decreasing functional impairments, leading to pain relief, easing depression, decreasing time to flatulence following surgery and improving sleep quality (112).

Several traditional Chinese medicines, such as artemisinin $(113,114)$, Danshen $(113,115)$, glossy Ganoderma (116), and Huangqi $(117,118)$, have been used as anticancer therapies, such as being used as supplementary anticancer drugs and psychobehavioral interventions (112-118). This suggests the potential for diosgenin as a traditional Chinese medicine in clinical antitumor use.
At present, the incidence rate of some kinds of cancers in certain areas is increasing, such as colorectal cancer in Latin America, Asia, Eastern Europe, breast cancer in low-income countries, gastric cardia cancer in the United States and many European countries (119-121), besides, cancer remains a serious threat to human health and mortality (1). Cancer is often discovered in the late stages, and in the majority of cases, the primary cancer has metastasized into adjacent lymph nodes and other sites (3). Diosgenin, as a main component of a traditional Chinese medicine, has a suppressing effect on tumor metastasis. Numerous anticancer drugs that are currently used have toxic side effects, and certain types of cancer develop resistance to the drugs to a certain extent (30). Diosgenin may have the capability of avoiding these shortcomings $(30,110)$.

The clinical use of diosgenin as an anticancer treatment requires further study and testing. Given the multiple pathways and various targets of diosgenin, future research should investigate its potential function in cancer inhibition.

\section{Conclusions and prospects}

Diosgenin may act on: i) Src by inhibiting its phosphorylation ii) the FAK pathway by inhibiting the expression of associated molecules and activation of the pathway; and iii) NF- $\kappa B$ by inhibiting its level and activity, in addition to other pathways. Furthermore, Src, the FAK pathway and NF- $\mathrm{KB}$ have inter-relationships. The inhibition of diosgenin on $\mathrm{Src}$, the FAK pathway and NF- $\kappa$ B has a negative effect on the main switch Cortactin, thus inhibiting invadopodia formation in various cancer cells.

Future studies should examine the mechanism of diosgenin inhibition of invadopodia formation to suppress the metastasis of primary tumors. These findings will aid subsequent clinical applications, particularly pharmaceutical use.

\section{Acknowledgements}

Not applicable.

\section{Funding}

The present study was supported by Jilin University, (Changchun, China; grant nos. 2017QNYB016 and 201910183200) and the Department of Education of Jilin Province (Changchun, China; grant no. 2016456).

\section{Availability of data and materials}

The data used and/or analyzed during the present study are available from the corresponding author upon reasonable request.

\section{Authors' contributions}

YL completed the collection and analysis of relevant literature and wrote the first draft of the manuscript. DW, XM and XW participated in the analysis and collation of the literature. HL, LH and HX critically analyzed the relevant literature and the manuscript structure. JZ revised the manuscript. All authors read and approved the final manuscript. 


\section{Ethics approval and consent to participate}

Not applicable.

\section{Patient consent for publication}

Not applicable.

\section{Competing interests}

The authors declare that they have no competing interests.

\section{References}

1. Torre LA, Siegel RL, Ward EM and Jemal A: Global cancer incidence and mortality rates and trends-an update. Cancer Epidemiol Biomarkers Prev 25: 16-27, 2016.

2. Ferlay J, Soerjomataram I, Dikshit R, Eser S, Mathers C, Rebelo M, Parkin DM, Forman D and Bray F: Cancer incidence and mortality worldwide: Sources, methods and major patterns in GLOBOCAN 2012. Int J Cancer 136: E359-E386, 2015.

3. Zeeshan R and Mutahir Z: Cancer metastasis-tricks of the trade. Bosn J Basic Med Sci 17: 172-182, 2017.

4. Dudjak LA: Cancer metastasis. Semin Oncol Nurs 8: 40-50, 1992

5. Yang J and Weinberg RA: Epithelial-mesenchymal transition: At the crossroads of development and tumor metastasis. Dev Cell 14: 818-829, 2008.

6. Valastyan S and Weinberg R: Tumor metastasis: Molecular insights and evolving paradigms. Cell 147: 275-292, 2011.

7. Linder S and Wiesner C: Tools of the trade: Podosomes as multipurpose organelles of monocytic cells. Cell Mol Life Sci 72 121-135, 2015.

8. Popow-Woźniak A, Mazur AJ, Mannherz HG, MalickaBłaszkiewicz M and Nowak D: Cofilin overexpression affects actin cytoskeleton organization and migration of human colon adenocarcinoma cells. Histochem Cell Biol 138: 725-736, 2012.

9. Leong H, Robertson A, Stoletov K, Leith SJ, Chin CA, Chien AE, Hague MN, Ablack A, Carmine-Simmen K, McPherson VA, et al: Invadopodia are required for cancer cell extravasation and are a therapeutic target for metastasis. Cell Rep 8: 1558-1570, 2014.

10. Parekh A and Weaver AM: Regulation of invadopodia by mechanical signaling. Exp Cell Res 343: 89-95, 2016.

11. Artym VV, Yamada KM and Mueller SC: ECM Degradation assays for analyzing local cell invasion. Methods Mol Biol 522: 211-219, 2009.

12. Beaty BT and Condeelis J: Digging a little deeper: The stages of invadopodium formation and maturation. Eur J Cell Biol 93: 438-444, 2014

13. Eddy RJ, Weidmann MD, Sharma VP and Condeelis JS: Tumor cell invadopodia: Invasive protrusions that orchestrate metastasis. Trends Cell Biol 27: 595-607, 2017.

14. Sharma V, Eddy R, Entenberg D, Kai M, Gertler FB and Condeelis J: Tks5 and SHIP2 regulate invadopodium maturation, but not initiation, in breast carcinoma cells. Curr Biol 23 . 2079-2089, 2013.

15. Hughes SK, Oudin MJ, Tadros J, Neil J, Del Rosario A, Joughin BA, Ritsma L, Wyckoff J, Vasile E, Eddy R, et al: PTP1B-dependent regulation of receptor tyrosine kinase signaling by the actin-binding protein Mena. Mol Biol Cell 26: 3867-3878, 2015.

16. Zervantonakis I, Sudo R, Rimchala T, Chung S and Kamm R: Abstract \#2269: A physiological relevant 3D in vitro model of cancer cell migration and interactions with endothelium. Cancer Res 69: 2269-2269, 2009.

17. Wang DD, Chen YB, Zhao JJ, Zhang XF, Zhu GC, Weng DS, Pan K, Lv L, Pan QZ, Jiang SS, et al: TES functions as a Mena-dependent tumor suppressor in gastric cancer carcinogenesis and metastasis. Cancer Commun (Lond) 39: 3, 2019.

18. Bravo-Cordero JJ, Magalhaes MA, Eddy RJ, Hodgson L and Condeelis J: Functions of cofilin in cell locomotion and invasion. Nat Rev Mol Cell Biol 14: 405-415, 2013.

19. Murphy DA and Courtneidge SA: The 'ins' and 'outs' of podosomes and invadopodia: Characteristics, formation and function. Nat Rev Mol Cell Biol 12: 413-426, 2011.

20. Linder S: The matrix corroded: Podosomes and invadopodia in extracellular matrix degradation. Trends Cell Biol 17: 107-117, 2007.
21. Baldassarre M, Pompeo A, Beznoussenko G, Castaldi C, Cortellino S, McNiven MA, Luini A and Buccione R: Dynamin participates in focal extracellular matrix degradation by invasive cells. Mol Biol Cell 14: 1074-1084, 2003.

22. Buccione R, Orth JD and McNiven MA: Foot and mouth: Podosomes, invadopodia and circular dorsal Ruffles. Nat Rev Mol Cell Biol 5: 647-657, 2004.

23. Chuang YY: Role of synaptojanin 2 in glioma cell migration and invasion. Cancer Res 64: 8271-8275, 2004.

24. Tu Y: The discovery of artemisinin (qinghaosu) and gifts from Chinese medicine. Nat Med 17: 1217-1220, 2011

25. Wang YJ, Pan KL, Hsieh TC, Chang TY, Lin WH and Hsu JT: Diosgenin, a plant-derived sapogenin, exhibits antiviral activity in vitro against hepatitis c virus. J Nat Prod 74: 580-584, 2011.

26. Cayen MN and Dvornik D: Effect of diosgenin on lipid metabolism in rats. J Lipid Res 20: 162, 1979.

27. Chen Y, Tang YM, Yu SL, Han YW, Kou JP, Liu BL and Yu BY: Advances in the pharmacological activities and mechanisms of diosgenin. Chin J Nat Med 13: 578-587, 2015.

28. Li F, Fernandez PP, Rajendran P, Hui KM and Sethi G: Diosgenin, a steroidal saponin, inhibits STAT3 signaling pathway leading to suppression of proliferation and chemosensitization of human hepatocellular carcinoma cells. Cancer Lett 292: 197-207, 2010.

29. Tao X, Yin L, Xu L and Peng J: Dioscin: A diverse acting natural compound with therapeutic potential in metabolic diseases, cancer, inflammation and infections. Pharmacol Res 137: 259-269, 2018.

30. Sethi G, Shanmugam MK, Warrier S, Merarchi M, Arfuso F, Kumar AP and Bishayee A: Pro-Apoptotic and Anti-cancer properties of diosgenin: A comprehensive and critical review. Nutrients 10: 645, 2018

31. Ma HY, Zhou LL and Wang BX: Antagonistic effect of DX and diosgenin on hyperlipidemia induced by cholesterol in vivo and on blood platelet aggregation in vitro. Chin J Hos Pharmacy 22: 323-325, 2002.

32. Raju J and Mehta R: Cancer chemopreventive and therapeutic effects of diosgenin, a food saponin. Nutr Cancer 61: 27-35, 2009.

33. Chen PS, Shih YW, Huang HC and Cheng HW: Diosgenin, a steroidal saponin, inhibits migration and invasion of human prostate cancer pc-3 cells by reducing matrix metalloproteinases expression. PLoS One 6: e20164, 2011.

34. Nie C, Zhou J, Qin X, Shi X, Zeng Q, Liu J, Yan S and Zhang L: Diosgenin-induced autophagy and apoptosis in a human prostate cancer cell line. Mol Med Rep 14: 4349-4359, 2016.

35. Sun GC, Jan CR and Liang WZ: Exploring the impact of a naturally occurring sapogenin diosgenin on underlying mechanisms of $\mathrm{Ca}^{2+}$ movement and cytotoxicity in human prostate cancer cells. Environ Toxicol 35: 395-403, 2020.

36. Hu M, Xu L, Yin L, Qi Y, Li H, Xu Y, Han X, Peng J and Wan X: Cytotoxicity of dioscin in human gastric carcinoma cells through death receptor and mitochondrial pathways. J Appl Toxicol 33: 712-722, 2013

37. Zhao X, Xu L, Zheng L, Yin L, Qi Y, Han X, Xu Y and Peng J: Potent effects of dioscin against gastric cancer in vitro and in vivo. Phytomedicine 23: 274-282, 2016.

38. Rahmati-Yamchi M, Ghareghomi S, Haddadchi G, Milani M, Aghazadeh M and Daroushnejad H: Fenugreek extract diosgenin and pure diosgenin inhibit the htert gene expression in a549 lung cancer cell line. Mol Biol Rep 41: 6247-6252, 2014.

39. Xu L, Xu D, Li Z, Gao Y and Chen H: Synthesis and potent cytotoxic activity of a novel diosgenin derivative and its phytosomes against lung cancer cells. Beilstein J Nanotechnol 10: 1933-1942, 2019.

40. Srinivasan S, Koduru S, Kumar R, Venguswamy G, Kyprianou N and Damodaran C: Diosgenin targets Akt-mediated prosurvival signaling in human breast cancer cells. Int J Cancer 125: 961-967, 2009.

41. Swamy MV, Patlolla JM, Jayadev R, Marcus LA, Choi CI and Rao CV: Chemoprevention of colon cancer by diosgenin, a steroidal saponin constituent of fenugreek. Cancer Res: 65, 2005.

42. Shishodia S and Aggarwal BB: Diosgenin inhibits osteoclastogenesis, invasion, and proliferation through the downregulation of Akt, I kappa B kinase activation and NF-kappa B-regulated gene expression. Oncogene 25: 1463-1473, 2006.

43. Liagre B, Bertrand J, Leger DY and Beneytout JL: Diosgenin, a plant steroid, induces apoptosis in COX-2 deficient K562 cells with activation of the p38 MAP kinase signalling and inhibition of NF-kappaB binding. Int J Mol Med 16: 1095-1101, 2005.

44. Cai H, Gong L, Liu J, Zhou Q and Zheng Z: Diosgenin inhibits tumor angiogenesis through regulating GRP78-mediated HIF-1a and VEGF/VEGFR signaling pathways. Pharmazie 74: 680-684, 2019. 
45. Lepage C, Léger DY, Bertrand J, Martin F, Beneytout JL and Liagre B: Diosgenin induces death receptor-5 through activation of p38 pathway and promotes TRAIL-induced apoptosis in colon cancer cells. Cancer Lett 301: 193-202, 2011.

46. Fang K, Dong H, Jiang S, Li F, Wang D, Yang D, Gong J, Huang W and Lu F: Diosgenin and 5-Methoxypsoralen ameliorate insulin resistance through ER- $\alpha / \mathrm{PI} 3 \mathrm{~K} / \mathrm{Akt}$-signaling pathways in HepG2 cells. Evid Based Complement Alternat Med 2016: 7493694 2016.

47. Corbiere C, Liagre B, Bianchi A, Bordji K, Dauça M, Netter P and Beneytout JL: Different contribution of apoptosis to the antiproliferative effects of diosgenin and other plant steroids, hecogenin and tigogenin, on human 1547 osteosarcoma cells. Int J Oncol 22: 899-905, 2003.

48. Corbiere C, Liagre B, Terro F and Beneytout JL: Induction of antiproliferative effect by diosgenin through activation of $\mathrm{p} 53$, release of apoptosis-inducing factor (AIF) and modulation of caspase-3 activity in different human cancer cells. Cell Res 14 188-196, 2004

49. Wang WC, Liu SF, Chang WT, Shiue YL, Hsieh PF, Hung TJ, Hung CY, Hung YJ, Chen MF and Yang YL: The effects of diosgenin in the Regulation of renal proximal tubular fibrosis. Exp Cell Res 323: 255-262, 2014

50. He Z, Chen H, Li G, Zhu H, Gao Y, Zhang L and Sun J: Diosgenin inhibits the migration of human breast cancer MDA-MB-231 cells by suppressing Vav2 activity. Phytomedicine 21: 871-876, 2014.

51. Wani SA and Kumar P. Fenugreek: A review on its nutraceutical properties and utilization in various food products. J Saudi Soc Agricultural Sci 17: 97-106, 2018.

52. Wang C, Huo X, Wang L, Meng Q, Liu Z, Liu Q, Sun H, Sun P, Peng J and Liu K: Dioscin strengthens the efficiency of Adriamycin in MCF-7 and MCF-7/ADR cells through autophagy induction: More than just down-regulation of MDR1. Sci Rep 6 : 28403, 2016.

53. Belsches AP, Haskell MD and Parsons SJ: Role of c-Src tyrosine kinase in EGF-induced mitogenesis. Front Biosci 2: d501-d518, 1997

54. Yin M, Ma W and An L: Cortactin in cancer cell migration and invasion. Oncotarget 8: 88232-88243, 2015.

55. Chien HT, Cheng SD, Chuang WY, Liao CT, Wang HM and Huang SF: Clinical implications of fadd gene amplification and protein overexpression in taiwanese oral cavity squamous cell carcinomas. PLoS One 11: e0164870, 2016.

56. Bryce NS, Clark ES, Leysath JL, Currie JD, Webb DJ and Weaver AM: Cortactin promotes cell motility by enhancing lamellipodial persistence. Curr Biol 15: 1276-1285, 2005.

57. Uruno T, Liu J, Li Y, Smith N and Zhan X: Sequential interaction of actin-related proteins 2 and 3 (Arp2/3) complex with neural Wiscott-Aldrich syndrome protein (N-WASP) and cortactin during branched actin filament network formation. J Biol Chem 278: 26086-26093, 2003.

58. Cosenbinker LI and Kapus A: Cortactin: The gray eminence of the cytoskeleton. Physiology (Bethesda) 21: 352-361, 2006.

59. Mizutani K, Miki $\mathrm{H}, \mathrm{He} \mathrm{H}$, Maruta $\mathrm{H}$ and Takenawa T: Essential role of neural Wiskott-Aldrich syndrome protein in podosome formation and degradation of extracellular matrix in src-transformed fibroblasts. Cancer Res 62: 669-674, 2002.

60. Kinley AW, Weed SA, Weaver AM, Karginov AV, Bissonette E, Cooper JA and Parsons JT: Cortactin Interacts with WIP in regulating Arp2/3 activation and membrane protrusion. Curr Biol 13 384-393, 2003.

61. Lin J, Liu J, Wang Y, Zhu J, Zhou K, Smith N and Zhan X: Differential regulation of cortactin and N-WASP-mediated actin polymerization by missing in metastasis (MIM) protein. Oncogene 24: 2059-2066, 2005.

62. Buday L and Downward J: Roles of cortactin in tumor pathogenesis. Biochim Biophys Acta 1775: 263-273, 2007.

63. He Y, Ren Y, Wu B, Decourt B, Lee AC, Taylor A and Suter DM: Src and cortactin promote lamellipodia protrusion and filopodia formation and stability in growth cones. Mol Biol Cell 26: 3229-3244, 2015

64. Krueger EW, Orth JD, Cao $\mathrm{H}$ and McNiven MA: A Dynamin-Cortactin-Arp2/3 complex mediates actin reorganization in growth factor-stimulated cells. Mol Biol Cell 14: 1085-1096, 2013

65. Oser M, Yamaguchi H, Mader CC, Bravo-Cordero JJ, Arias M, Chen X, Desmarais V, van Rheenen J, Koleske AJ and Condeelis J: Cortactin regulates cofilin and N-WASp activities to control the stages of invadopodium assembly and maturation. J Cell Biol 186: 571-587, 2009.
66. Ayala I, Baldassarre M, Giacchetti G, Caldieri G, Tetè S, Luini A and Buccione R: Multiple regulatory inputs converge on cortactin to control invadopodia biogenesis and extracellular matrix degradation. J Cell Sci 121: 369-378, 2008.

67. Ren XL, Qiao YD, Li JY, Li XM, Zhang D, Zhang XJ, Zhu XH, Zhou WJ, Shi J, Wang W, et al: Cortactin recruits FMNL2 to promote actin polymerization and endosome motility in invadopodia formation. Cancer Lett 419: 245-256, 2018.

68. Desmarais V, Yamaguchi H, Oser M, Soon L, Mouneimne G, Sarmiento C, Eddy R and Condeelis J: N-WASP and cortactin are involved in invadopodium-dependent chemotaxis to EGF In breast tumor cells. Cell Motil Cytoskeleton 66: 303-316, 2009.

69. Uruno T, Liu J, Zhang P, Fan YX, Egile C, Li R, Mueller SC and Zhan X: Activation of Arp2/3 complex-mediated actin polymerization by cortactin. Nat Cell Biol 3: 259-266, 2001.

70. Weaver AM, Karginov AV, Kinley AW, Weed SA, Li Y, Parsons JT and Cooper JA: Cortactin promotes and stabilizes Arp2/3-induced actin filament network formation. Curr Biol 11: 370-374, 2001

71. Artym VV, Zhang Y, Seillier-Moiseiwitsch F, Yamada KM and Mueller SC: dynamic interactions of cortactin and membrane type 1 matrix metalloproteinase at invadopodia: Defining the stages of invadopodia formation and function. Cancer Res 66: 3034-3043, 2006.

72. Khaitlina SY: Intracellular transport based on actin polymerization. Biochemistry (Mosc) 79: 917-927, 2014.

73. Ren G, Crampton MS and Yap AS: Cortactin: Coordinating adhesion and the actin cytoskeleton at cellular protrusions. Cell Motil Cytoskeleton 66: 865-873, 2009.

74. Tehrani S, Faccio R, Chandrasekar I, Ross FP and Cooper JA: Cortactin has an essential and specific role in osteoclast actin assembly. Mol Biol Cell 17: 2882-2895, 2006.

75. van Rossum AG, Moolenaar WH and Schuuring E: Cortactin affects cell migration by regulating intercellular adhesion and cell spreading. Exp Cell Res 312: 1658-1670, 2006.

76. Steven M: Markwell; Amanda Gatesman Ammer, Interval ET, Schafer DA Hames RA and Weed SA: Abstract 5067: Casein kinase 2 alpha phosphorylation of cortactin governs actin cytoskeletal regulation of invadopodia function. Cancer Res 76 (14 Suppl): S5067-S5067, 2016

77. Jeannot $\mathrm{P}$ and Besson $\mathrm{A}$ : Cortactin function in invadopodia. Small GTPases 11: 256-270, 2020.

78. Meng DF, Xie P, Peng LX, Sun R, Luo DH, Chen QY, Lv X, Wang L, Chen MY, Mai HQ, et al: CDC42-interacting protein 4 promotes metastasis of nasopharyngeal carcinoma by mediating invadopodia formation and activating EGFR signaling. J Exp Clin Cancer Res 36: 21, 2017

79. Genna A, Lapetina S, Lukic N, Twafra S, Meirson T, Sharma VP, Condeelis JS and Gil-Henn H: Pyk2 and FAK differentially regulate invadopodia formation and function in breast cancer cells. J Cell Biol 217: 375-395, 2018

80. Kempiak SJ, Yamaguchi H, Sarmiento C, Sidani M, Ghosh M, Eddy RJ, Desmarais V, Way M, Condeelis J and Segall JE: A Neural Wiskott-aldrich syndrome protein-mediated pathway for localized activation of actin polymerization that is regulated by cortactin. J Biol Chem 280: 5836-5842, 2005.

81. Wang W, Liu Y and Liao K: Tyrosine phosphorylation of cortactin by the FAK-Src complex at focal adhesions regulates cell motility. BMC Cell Biol 12: 49, 2011

82. Huang C, Ni Y, Wang T, Gao Y, Haudenschild CC and Zhan X: Down-regulation of the filamentous actin cross-linking activity of cortactin by Src-mediated tyrosine phosphorylation. J Biol Chem 272: 13911-13915, 1997.

83. Leger DY, Liagre B and Beneytout JL: Role of MAPKs and NF-kappaB in diosgenin-induced megakaryocytic differentiation and subsequent apoptosis in HEL cells. Int J Oncol 28: 201-207, 2006

84. Siar CH, Rahman ZA, Tsujigiwa H, Mohamed OM, Alblazi K, Nagatsuka $\mathrm{H}$ and $\mathrm{Ng} \mathrm{KH}$ : Invadopodia proteins, cortactin, $\mathrm{N}$-WASP and WIP differentially promote local invasiveness in ameloblastoma. J Oral Pathol Med 45: 591-598, 2016.

85. Tong Q, Qing Y, Wu Y, Hu X, Jiang L and Wu X: Dioscin inhibits colon tumor growth and tumor angiogenesis through regulating VEGFR2 and AKT/MAPK signaling pathways. Toxicol Appl Pharmacol 281: 166-173, 2014.

86. Farhan MA, Azad AK, Touret N and Murray AG: FGD5 Regulates VEGF Receptor-2 Coupling to PI3 kinase and receptor recycling. Arterioscler Thromb Vasc Biol 37: 2301-2310, 2017. 
87. Choi KW, Park HJ, Jung DH, Kim TW, Park YM, Kim BO, Sohn EH, Moon EY, Um SH, Rhee DK and Pyo S: Inhibition of TNF- $\alpha$-induced adhesion molecule expression by diosgenin in mouse vascular smooth muscle cells via downregulation of the MAPK, Akt and NF- $\kappa \mathrm{B}$ signaling pathways. Vascul Pharmacol 53: 273-280, 2010.

88. Li S, Cheng B, Hou L, Huang L, Cui Y, Xu D, Shen X and Li S: Dioscin inhibits colon cancer cells' growth by reactive oxygen species-mediated mitochondrial dysfunction and p38 and JNK pathways. Anticancer Drugs 29: 234-242, 2018.

89. Lin SC, Gou GH, Hsia CW, Ho CW, Huang KL, Wu YF, Lee SY and Chen YH: Simulated microgravity disrupts cytoskeleton organization and increases apoptosis of rat neural crest stem cells via upregulating CXCR4 expression and RhoA-ROCK1-p38 MAPK-p53 signaling. Stem Cells Dev 25: 1172-1193, 2016.

90. Chiang CT, Way TD, Tsai SJ and Lin JK: Diosgenin, a naturally occurring steroid, suppresses fatty acid synthase expression in HER2-overexpressing breast cancer cells through modulating Akt, mTOR and JNK phosphorylation. FEBS Lett 581: 5735-5742, 2007.

91. Wang YC, Wu DW, Wu TC, Wang L, Chen CY and Lee H: Dioscin overcome TKI resistance in EGFR-mutated lung adenocarcinoma cells via Down-regulation of tyrosine phosphatase SHP2 expression. Int J Biol Sci 14: 47-56, 2018.

92. Gao M, Chen L, Yu H, Sun Q, Kou J and Yu B: Diosgenin down-regulates NF-kB p65/p50 and p38MAPK pathways and attenuates acute lung injury induced by lipopolysaccharide in mice. Int Immunopharmacol 15: 240-245, 2013.

93. Song JS, Ma L, Kou J and Yu BY: Diosgenin reduces leukocytes adhesion and migration linked with inhibition of intercellular adhesion molecule- 1 expres-sion and NF-kB p65 activation in endothelial cells. Chin J Nat Med 10: 142-149, 2012.

94. Tavora B, Reynolds LE, Batista S, Demircioglu F, Fernandez I, Lechertier T, Lees DM, Wong PP, Alexopoulou A and Elia G, et al: Endothelial-cell FAK targeting sensitizes tumours to DNA-damaging therapy. Nature 514: 112-116, 2014.

95. Liu Z, Zhang HM, Yuan J, Lim T, Sall A, Taylor GA and Yang D: Focal adhesion kinase mediates the interferon-gamma-inducible GTPase-induced phosphatidylinositol 3-kinase/Akt survival pathway and further initiates a positive feedback loop of NF-kappaB activation. Cell Microbiol 10: 1787-1800, 2010.

96. Chen J, Zhang W, Wang Y, Zhao D, Wu M, Fan J, Li J, Gong Y, Dan N, Yang D, et al: The diacylglycerol kinase $\alpha$ $(\mathrm{DGK} \alpha) / \mathrm{Akt} / \mathrm{NF}-\kappa \mathrm{B}$ feedforward loop promotes esophageal squamous cell carcinoma (ESCC) progression via FAK-dependent and FAK-independent manner. Oncogene 38: 2533-2550, 2019.

97. Irby RB and Yeatman TJ: Role of Src expression and activation in human cancer. Oncogene 19: 5636-5642, 2000.

98. Zhou X, Yang F, Zhang Q, Miao Y, Hu X, Li A, Hou G, Wang Q and Kang J: FAM129B promoted tumor invasion and proliferation via facilitating the phosphorylation of FAK signaling and associated with adverse clinical outcome of non-small cell lung cancer patients. Onco Targets Ther 11: 7493-7501, 2018.

99. Avizienyte E and Frame MC: Src and FAK signalling controls adhesion fate and the epithelial-to-mesenchymal transition. Curr Opin Cell Biol 17: 542-547, 2005.

100. Mitra SK and Schlaepfer DD: Integrin-regulated FAK-Src signaling in normal and cancer cells. Curr Opin Cell Biol 18 516-523 2006

101. Liang Y, Yi L, Liu P, Jiang L, Wang H, Hu A, Sun C and Dong J: CX3CL1 involves in breast cancer metastasizing to the spine via the Src/FAK signaling pathway. J Cancer 9: 3603-3612, 2018

102. Saijo K, Schmedt C, Su IH, Karasuyama H, Lowell CA, Reth M, Adachi T, Patke A, Santana A and Tarakhovsky A: Essential role of Src-family protein tyrosine kinases in NF-kappaB activation during B cell development. Nat Immunol 4: 274-279, 2003.

103. Chen L, Chen H and Liu F: RACK1 to modulate expression of MMP10 via Src/NF- $\kappa$ B pathway in gastric cancer. J Clin Oncol 35 (15_suppl): e15529, 2017.

104. Lai SW, Bamodu OA, Tsai WC, Chang YM, Lee WH, Yeh CT and Chao TY: The therapeutic targeting of the FGFR1/Src/NF- $\mathrm{BB}$ signaling axis inhibits pancreatic ductal adenocarcinoma stemness and oncogenicity. Clin Exp Metastasis 35: 663-677, 2018.
105. Peng X, Zhang Q, Zeng Y, Li J, Wang L and Ai P: Evodiamine inhibits the migration and invasion of nasopharyngeal carcinoma cells in vitro via repressing MMP-2 expression. Cancer Chemother Pharmacol 76: 1173-1184, 2015.

106. Lian S, Xia Y, Khoi PN, Ung TT, Yoon HJ, Kim NH, Kim KK and Jung YD: Cadmium induces matrix metalloproteinase-9 expression via ROS-dependent EGFR, NF-KB, and AP-1 pathways in human endothelial cells. Toxicology 338: 104-116, 2015.

107. Hung CY, Lee CH, Chiou HL, Lin CL, Chen PN, Lin MT, Hsieh YH and Chou MC: Praeruptorin-B Inhibits 12-O-tetradecanoylphorbol-13-Acetate-induced cell invasion by targeting $\mathrm{AKT} / \mathrm{NF}-\mathrm{\kappa B}$ via matrix metalloproteinase-2/-9 expression in human cervical cancer cells. Cell Physiol Biochem 52. 1255-1266, 2019.

108. Sabir N, Hussain T, Mangi MH, Zhao D and Zhou X: Matrix metalloproteinases: Expression, regulation and role in the immunopathology of tuberculosis. Cell Prolif 52: e12649, 2019.

109. Liu LP, Liang HF, Chen XP, Zhang WG, Yang SL, Xu T and Ren L: The role of NF-kappaB in Hepatitis B virus $X$ protein-mediated upregulation of VEGF and MMPs. Cancer Invest 28: 443-451, 2010.

110. Zhang X, Jin M, Tadesse N, Dang J, Zhou T, Zhang H, Wang S, Guo Z and Ito Y: Dioscorea zingiberensis C. H. Wright: An overview on its traditional use, phytochemistry, pharmacology, clinical applications, quality control, and toxicity. J Ethnopharmacol 220: 283-293, 2018.

111. Wu FC and Jiang JG: Effects of diosgenin and its derivatives on atherosclerosis. Food Funct 10: 7022-7036., 2019

112. Tao W, Luo X, Cui B, Liang D, Wang C, Duan Y, Li X, Zhou S, Zhao M, Li Y, et al: Practice of traditional Chinese medicine for psycho-behavioral intervention improves quality of life in cancer patients: A systematic review and meta-analysis. Oncotarget 6: 39725-39739, 2015.

113. Wang J, Wong YK and Liao F: What has traditional Chinese medicine delivered for modern medicine? Expert Rev Mol Med 20: e4, 2018.

114. White NJ: Qinghaosu (Artemisinin): The price of success. Science 320: 330-334, 2008 .

115. Zhou L, Zuo Z and Chow MS: Danshen: An overview of its chemistry, pharmacology, pharmacokinetics, and clinical use. J Clin Pharmacol 45: 1345-1349, 2005.

116. Yi-Lan LI, Shan-Shan Q and Guo-Xing LI: Effect of glossy ganoderma on antitumor and immune function in mice. Chin J Prevention Control Chronic Non-Communicable Dis, 2004.

117. Liu P, Zhao $\mathrm{H}$ and Luo Y: Anti-aging implications of astragalus membranaceus (Huangqi): A Well-known Chinese tonic. Aging Dis 8: 868-886, 2017.

118. Wang K, Wu J, Duan X, Wu J, Zhang D, Zhang X and Zhang B Huangqi injection in the treatment of chronic heart failure: A systematic review and meta-analysis. Medicine (Baltimore) 96: e8167, 2017.

119. de Martel C, Forman D and Plummer M: Gastric cancer: Epidemiology and risk factors. Gastroenterol Clin North Am 42: 219-240, 2013

120. Camargo MC, Anderson WF, King JB, Correa P, Thomas CC, Rosenberg PS, Eheman CR and Rabkin CS: Divergent trends for gastric cancer incidence by anatomical subsite in US adults. Gut 60: 1644-169, 2011.

121. Steevens J, Botterweck AAM, Dirx MJ, van den Brandt PA and Schouten LJ: Trends in incidence of oesophageal and stomach cancer subtypes in Europe. Eur J Gastroenterol Hepatol 22: 669-678, 2010.

This work is licensed under a Creative Commons Attribution-NonCommercial-NoDerivatives 4.0 International (CC BY-NC-ND 4.0) License. 